\title{
PET/MRI in prostate cancer: a systematic review and meta-analysis
}

\author{
${\text { Laura Evangelista }{ }^{1} \text { (D) Fabio Zattoni }{ }^{2} \cdot \text { Gianluca Cassarino }^{1} \cdot \text { Paolo Artioli }^{1} \cdot \text { Diego Cecchin }^{1} \cdot \text { Fabrizio dal Moro }}^{2,3}$. \\ Pietro Zucchetta ${ }^{1}$
}

Received: 2 July 2020 / Accepted: 31 August 2020 / Published online: 8 September 2020

(C) The Author(s) 2020

\begin{abstract}
Aim In recent years, the clinical availability of scanners for integrated positron emission tomography (PET) and magnetic resonance imaging (MRI) has enabled the practical potential of multimodal, combined metabolic-receptor, anatomical, and functional imaging to be explored. The present systematic review and meta-analysis summarize the diagnostic information provided by PET/MRI in patients with prostate cancer (PCa).

Materials and methods A literature search was conducted in three different databases. The terms used were "choline" or "prostate-specific membrane antigen - PSMA" AND "prostate cancer" or "prostate" AND "PET/MRI" or "PET MRI" or "PET-MRI" or "positron emission tomography/magnetic resonance imaging." All relevant records identified were combined, and the full texts were retrieved. Reports were excluded if (1) they did not consider hybrid PET/MRI; or (2) the sample size was < 10 patients; or (3) the raw data were not enough to enable the completion of a $2 \times 2$ contingency table.

Results Fifty articles were eligible for systematic review, and 23 for meta-analysis. The pooled data concerned 2104 patients. Initial disease staging was the main indication for PET/MRI in 24 studies. Radiolabeled PSMA was the tracer most frequently used. In primary tumors, the pooled sensitivity for the patient-based analysis was $94.9 \%$. At restaging, the pooled detection rate was $80.9 \%$ and was higher for radiolabeled PSMA than for choline ( $81.8 \%$ and $77.3 \%$, respectively).

Conclusions PET/MRI proved highly sensitive in detecting primary $\mathrm{PCa}$, with a high detection rate for recurrent disease, particularly when radiolabeled PSMA was used.
\end{abstract}

Keywords Prostate cancer $\cdot$ Positron emission tomography $\cdot$ Magnetic resonance imaging $\cdot$ PSMA $\cdot$ Choline

\section{Introduction}

The availability of tracers other than $18 \mathrm{f}$-fluorodeoxyglucose (FDG) suggests new opportunities for the diagnosis and

This article is part of the Topical Collection on Oncology - Genitourinary Electronic supplementary material The online version of this article (https://doi.org/10.1007/s00259-020-05025-0) contains supplementary material, which is available to authorized users.

Laura Evangelista

laura.evangelista@unipd.it

1 Nuclear Medicine Unit, Department of Medicine, Padova University Hospital, Via Giustiniani 2, Padova, Italy

2 Urology Unit, Department of Medicine, Udine University Hospital, Udine, Italy

3 Urology Unit, Department of Surgery, Oncology and Gastroenterology, University of Padova, Padova, Italy management of prostate cancer (PCa). The use of different radiopharmaceuticals, such as radiolabeled choline, or radiolabeled ligands of prostate-specific membrane antigen (PSMA), has a significant impact in various clinical settings, from initial staging to the detection of a biochemical recurrence, enabling personalized treatment planning, and metastasis-directed therapy (MDT) [1,2]. Such an approach relies on the diagnostic performance of the imaging modalities used to detect the real extent and location of metastases. Many studies on PCa patients have been conducted using PET/CT [3-5], but most clinical protocols consider magnetic resonance imaging (MRI) the principal imaging modality for staging and restaging of patients with PCa.

In recent years, the clinical availability of integrated PET/ MRI scanners has made it possible to explore the practical potential of multimodal, combined metabolic-receptor, anatomical, and functional imaging. The present systematic review and meta-analysis summarize the diagnostic information obtained with PET/MRI in PCa patients. 


\section{Materials and methods}

\section{Search strategy and study selection}

A literature search from 2013 up to 23rd March 2020 was conducted in the PubMed, Scopus, and Web of Science databases. The terms used were as follows: "choline" or "PSMA" AND "prostate cancer" or "prostate" AND "PET/MRI" or "PET MRI" or "PET-MRI" or "positron emission tomography/magnetic resonance imaging." The search was carried out with and without the addition of filters, such as English language only, type of article (original article, research article), and subjects (humans only). Three reviewers (L.E., F.Z., and P.A.) conducted the literature search, and two other reviewers (G.C. and D.C.) independently selected the studies to consider, excluding duplicate papers. Any discrepancy was solved by a consensus. After combining all the records identified, the full texts were retrieved and further assessed by four of the reviewers (F.Z, P.A., G.C., and L.E.).

One reviewer (L.E.) ran a new search across the databases, checking the references of the studies already selected, to ensure their eligibility. Reviews, clinical reports, abstracts of meetings, and editorials were excluded. The qualitative analysis excluded reports that did not consider hybrid PET/MRI scanners or that enrolled a very low number of patients $(<5)$. Studies were eligible for inclusion in the meta-analysis if all the following requirements were met: (i) a sample size of more than ten patients; and (ii) the article included enough raw data to enable the completion of a $2 \times 2$ contingency table (or the authors made said data available on request).

\section{Data extraction}

General details were retrieved for each study considered, such as generic data (authors, journal name, year of publication, country, and study design), patients' characteristics (number of patients and their mean or median age), disease phase (i.e., staging or restaging), type of treatment, mean or median PSA level at the time of PET, and radiotracer used for PET/MRI. A quality assessment on the studies was performed using the Quality Assessment of Diagnostic Accuracy Studies 2 (QUADAS-2) [6]. Data extraction and quality assessment were done independently by three reviewers (L.E., F.Z., G.C.), and differences were solved by discussion.

\section{Statistical methods}

The pooled detection rate of PET/MRI, with its sensitivities, specificities, and $95 \%$ confidence intervals (CIs), with both radiolabeled choline and radiolabeled PSMA, was calculated using random effects analysis. Heterogeneity was tested using the $\chi^{2}$ and the $I^{2}$ tests. The $\chi^{2}$ test provided an estimate of the between-study variance, and the $I^{2}$ test measured the proportion of inconsistency in individual studies that cannot be explained by chance. The values for heterogeneity $\left(I^{2}\right)$ of $25 \%, 50 \%$, and $75 \%$ were considered low, moderate, and high, respectively [7]. Publication bias was assessed using Deeks' funnel plot asymmetry test, and a $P$ value above 0.05 suggested the absence of any publication bias. All statistical analyses were performed using the Meta-DiSc ${ }^{\circledR}$ version 1.4 (developed by the Clinical Biostatistics Unit at Ramón y Cajal Hospital, Madrid) and Comprehensive Meta-Analysis (CMA) software version 3.3.070 (Biostat, Englewood, NJ, USA).

\section{Results}

\section{Qualitative results}

In total, 50 studies were eligible for qualitative analysis (Fig. 1, Table 1), 20 of them were prospective, and 30 were retrospective. Overall, the analysis concerned 2059 patients who underwent hybrid PET/MRI. Disease staging was the most common reason for the test ( $n=24$ studies; totally, 940 patients), followed by restaging ( $n=16$; totally 844 patients), and both staging and restaging ( $n=10$; totally 275 patients). Radiolabeled PSMA was used in the majority of cases $(n=34$ studies). In 25 studies, the main endpoint was the ability of PET/MRI to detect PCa, be it primary or recurrent disease. Comparisons were drawn between PET/CT and PET/MRI performed in the same populations in 7 reports.

\section{Methodological quality}

All 50 studies were assessed with the QUADAS-2 tool (Fig. 2). The risk of bias for patient selection was high in many papers $[10,15,19-21,23,24,31,37,40-42,44,49-51,53$, 55]. The flow and timing were also high in 17 studies [10, 15, 20-24, 26, 27, 31, 32, 35, 44, 45, 51-53]. The applicability of the studies was adequate in most cases, but unclear as regards the reference standard in 18 of them $[15,22-24,27,34-37$, $41-44,49,50,52,53,56]$.

\section{PET/MRI for initial staging}

In the present review, 15 studies dealt with PET/MRI used only in the staging setting for the purpose of detecting primary disease [11, 12, 14, 18, 29, 31, 33, 35, 38, 40, 44-47, 54, 57].

Integrated PET/MRI proved to be of greater diagnostic value in locating PCa than either multiparametric (mp) MRI $[11,14,18,29,35,44,45,54,58]$ or PET imaging alone [14, 18, 44]. 68Ga-PSMA-11 PET/MRI showed high lesion contrast and an excellent consistency in lesion detection [20]. Intense ${ }^{18} \mathrm{~F}$-labelled PSMA uptake on PET and mpMRI changes correlated strongly with the dominant lesion in the prostate glands of men undergoing imaging before surgery 
Fig. 1 The PRISMA method for study selection $(*$ filters, journal article/humans/last 5 years/ English language; **exclusion of reviews, no inclusion of PET/ MRI in the title and exclusion of clinical case)

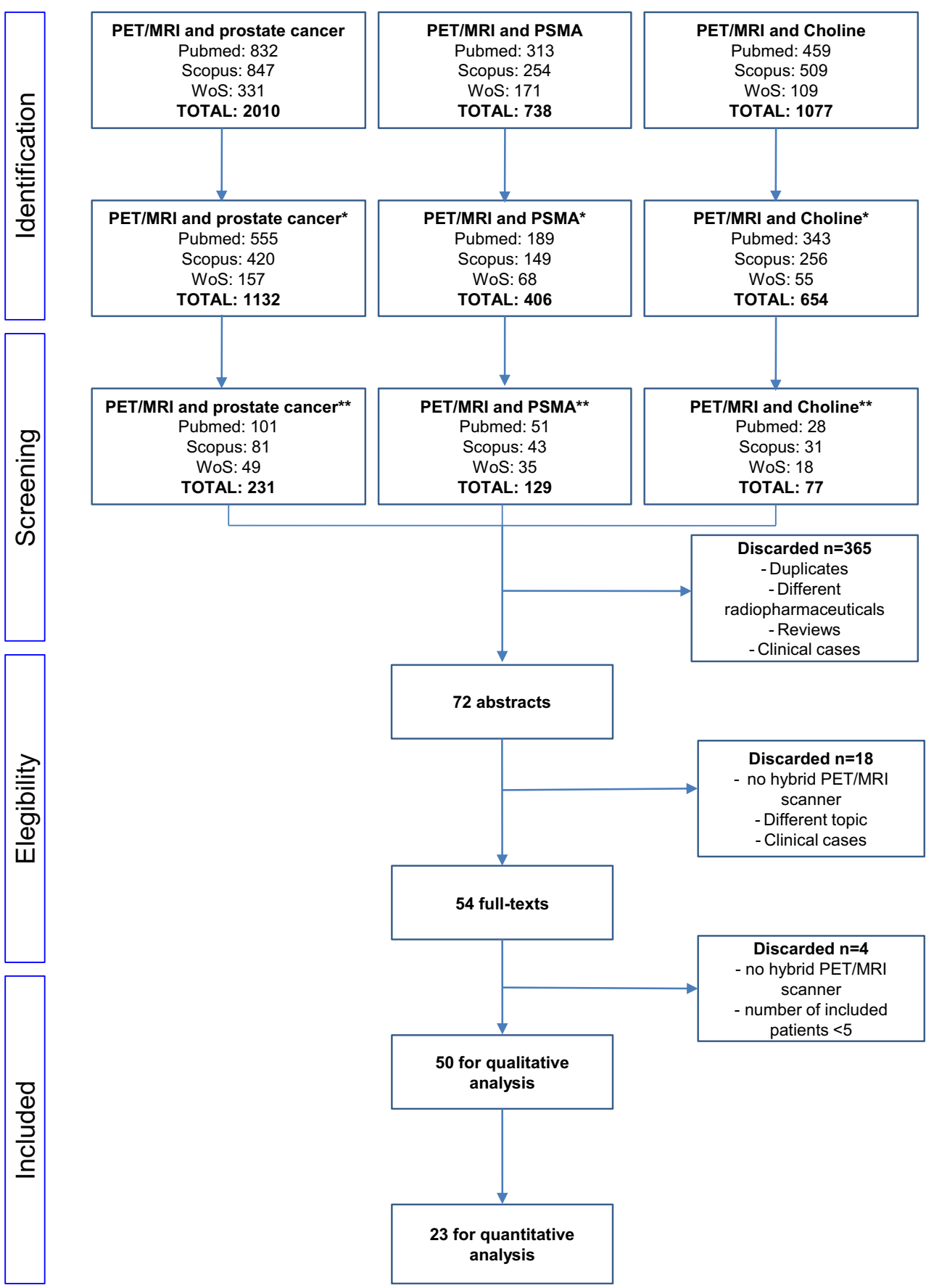

[31]. These results are consistent with other studies where PET was used to identify PCa lesions. For instance, Park et al. [38] reported that PCa was detected by ${ }^{68}$ Ga-PSMA-11 PET in all of their 33 patients, whereas mpMRI with the PIRADS (Prostate Imaging Reporting and Data System) pinpointed 4 or 5 lesions in 26 patients, but missed tumors in 3. Similarly, Ferrero et al. [47] found primary tumors PSMA-negative in only 3 of 60 patients, thus reaching a detection rate of $95 \%$.

The assessment of extracapsular extension, tumor grade, and Gleason score plays an important part in treatment decisions, and in distinguishing aggressive from indolent disease. In one study, extracapsular spread of PCa was detected better with ${ }^{68} \mathrm{Ga}$-PSMA-11 PET/MRI than with mpMRI (69 vs. 46\%) [54]. In another study, PET and PET/MRI produced a considerably lower proportion of equivocal results (i.e., PIRADS 3) than mpMRI [35].

PET/MRI may have also an important role in detecting local and distant metastases. From a visual inspection of 60 patients' imaging results, ${ }^{68} \mathrm{Ga}-\mathrm{PSMA}-11 \mathrm{PET} / \mathrm{MRI}$ revealed positive lymph nodes in 8 patients, with only one patient subsequently resulting false-positive. Most nodes were located in 
(2)

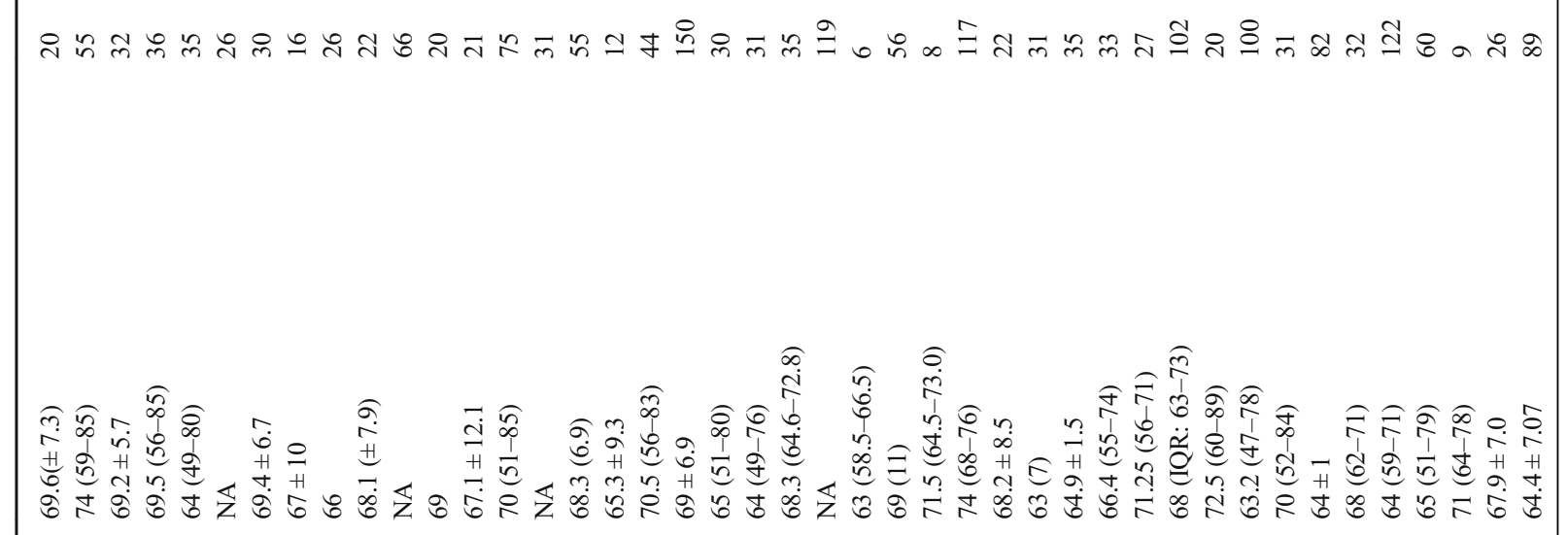

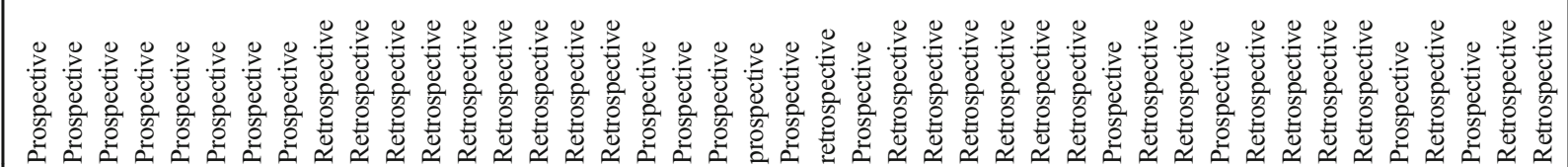

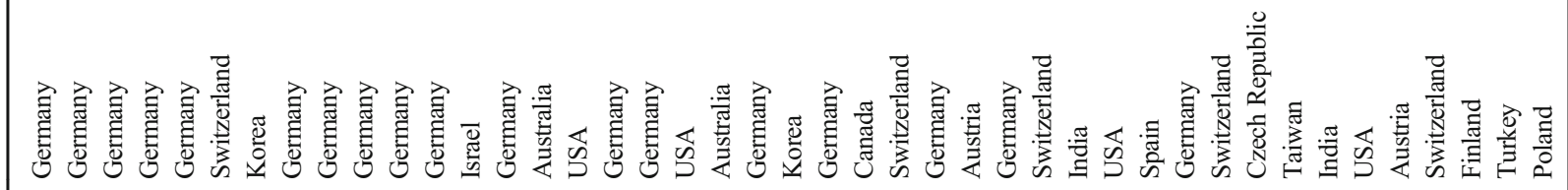

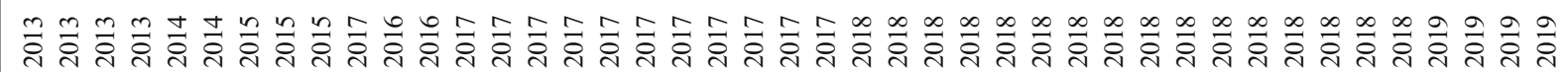

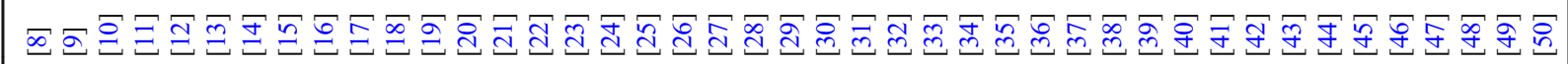

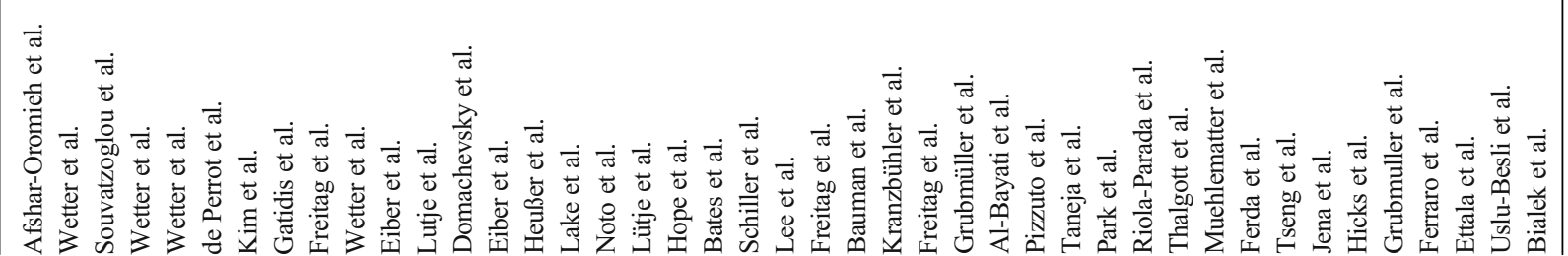




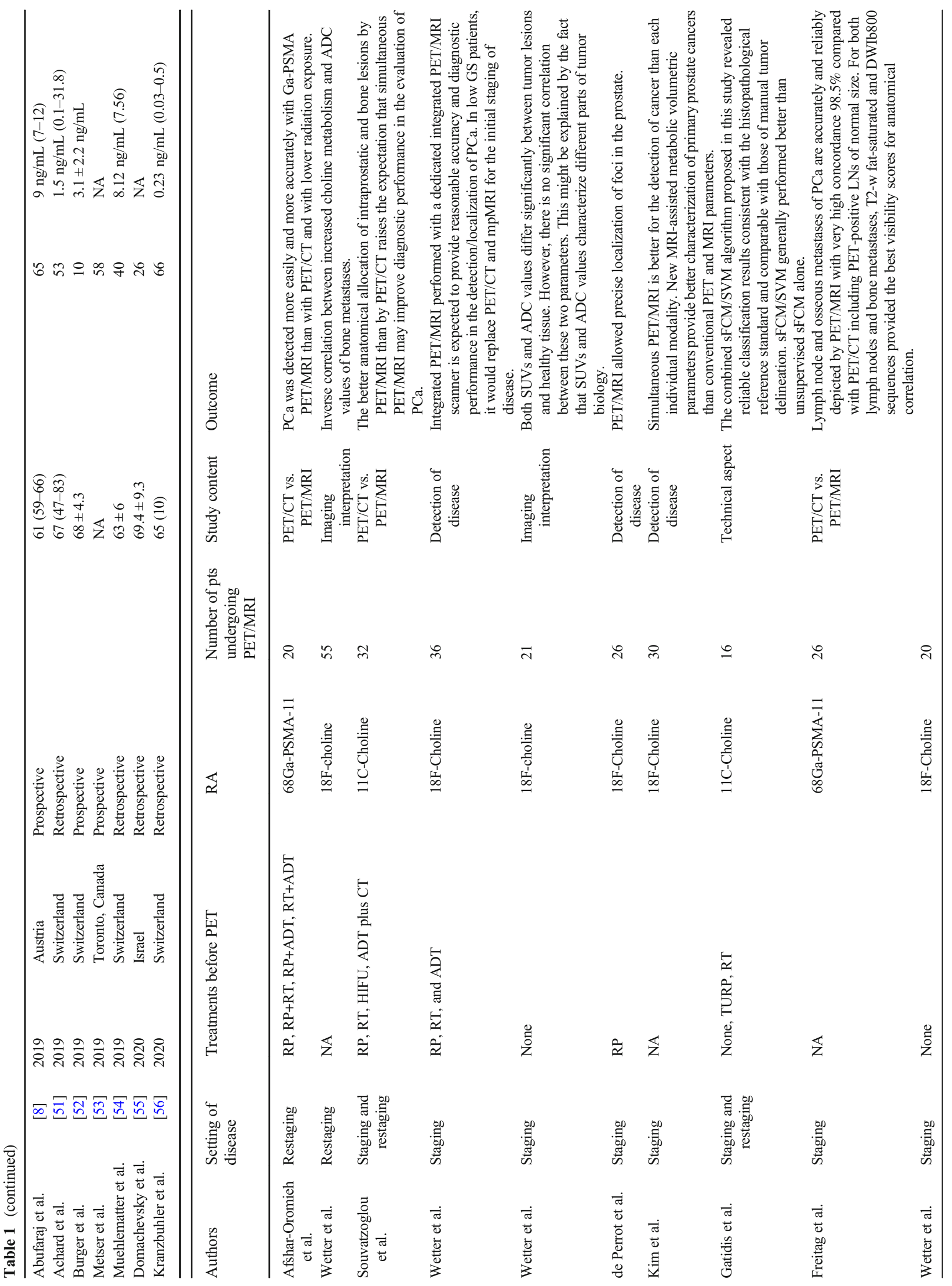




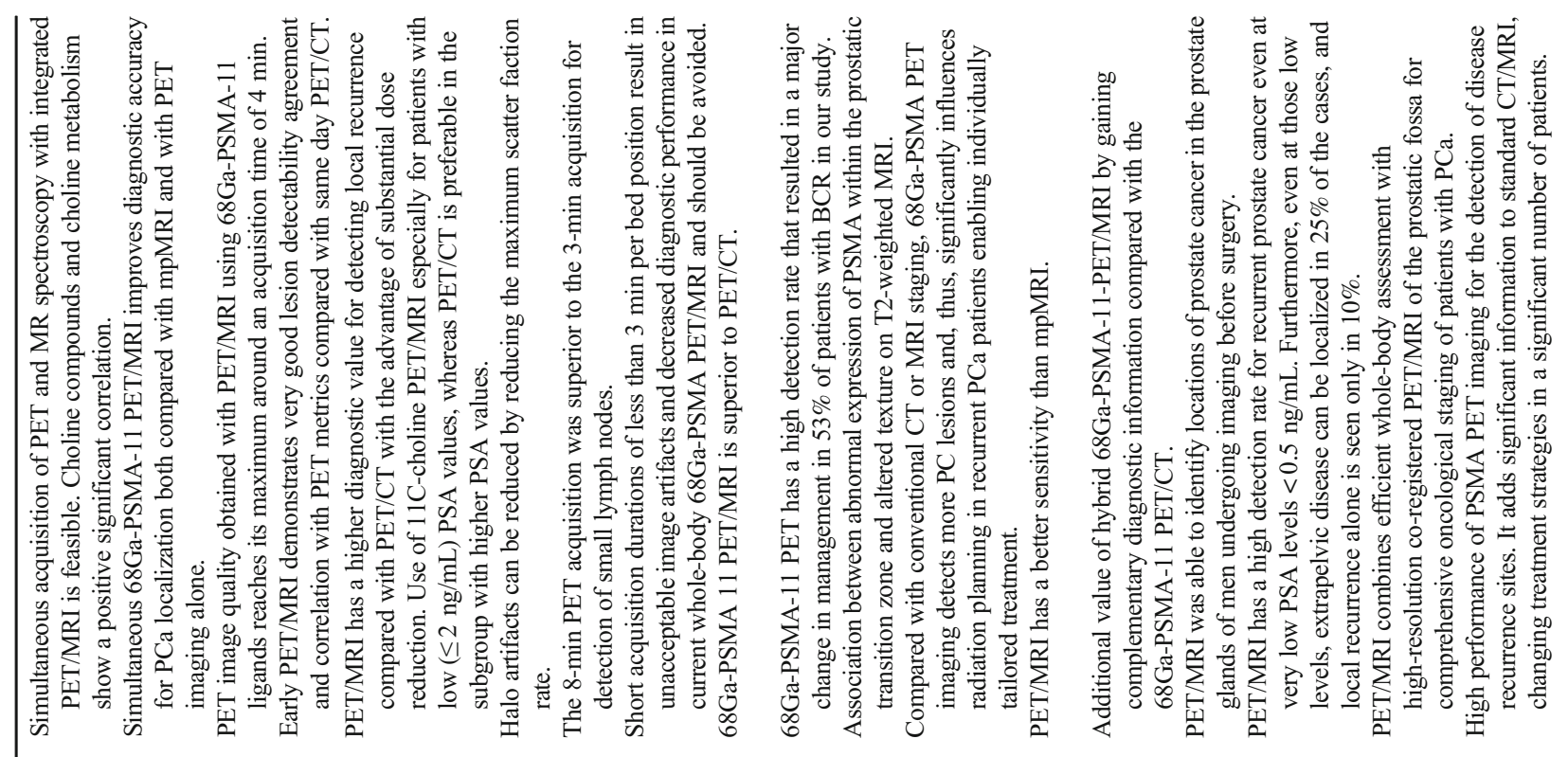

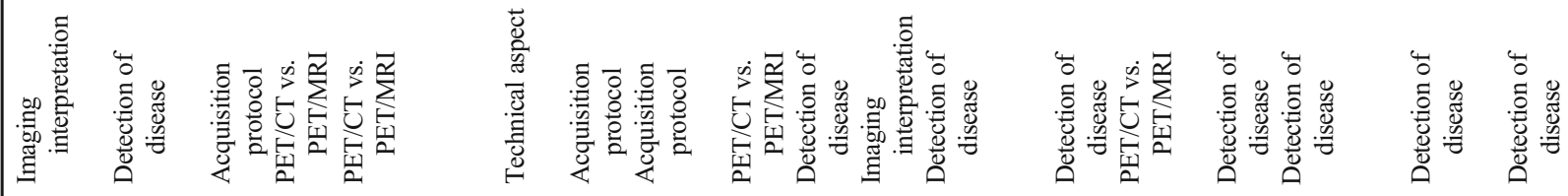

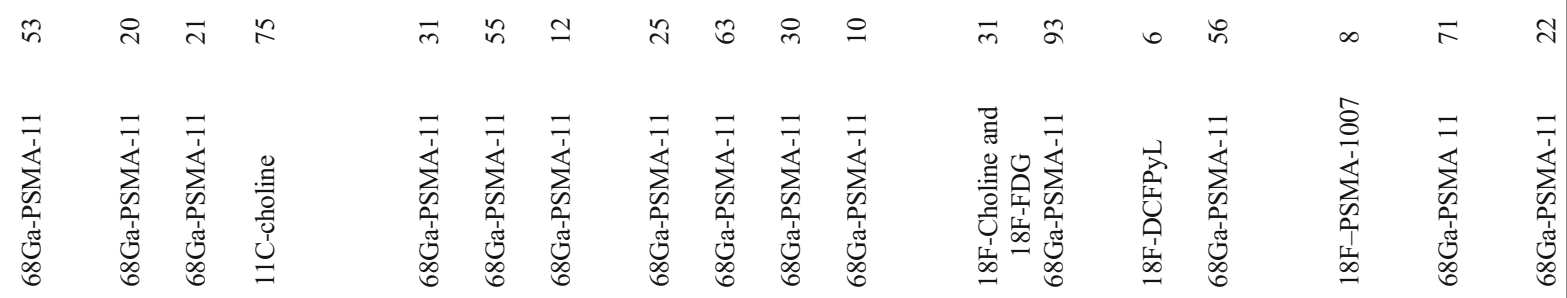

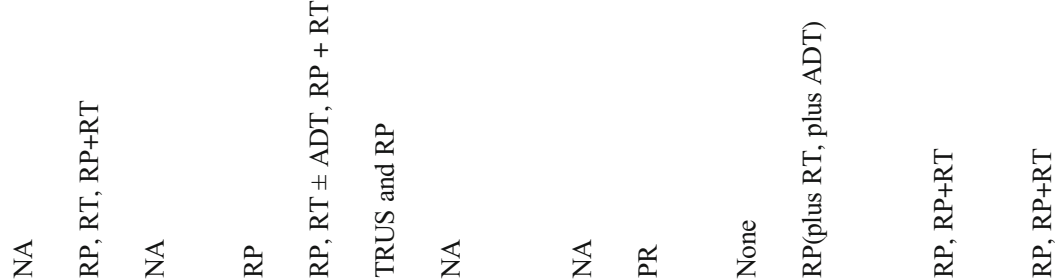



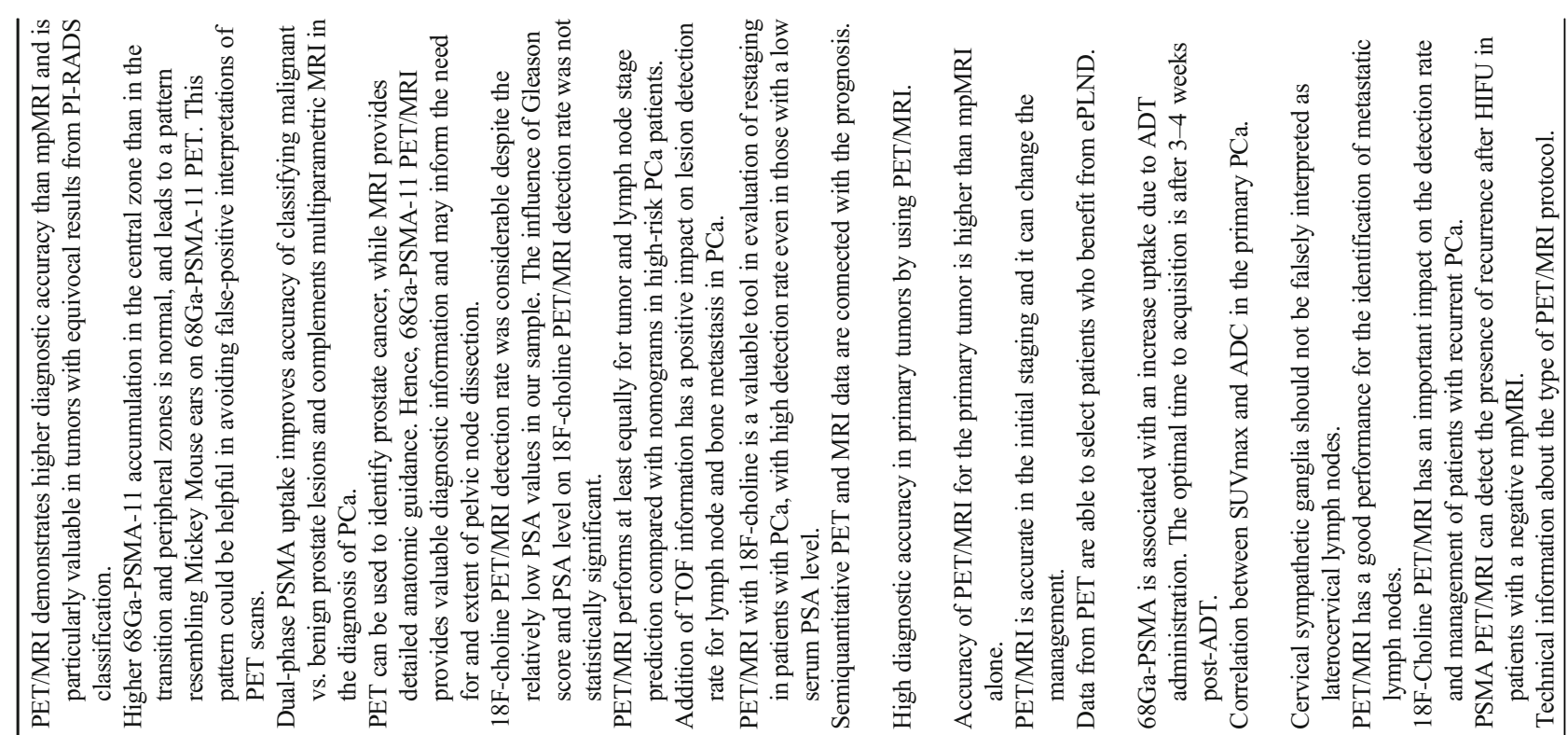

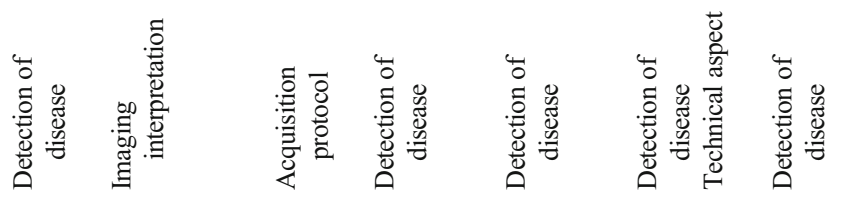
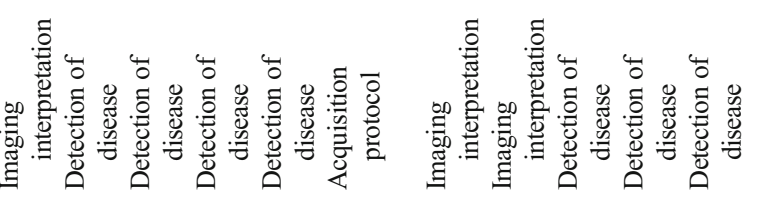

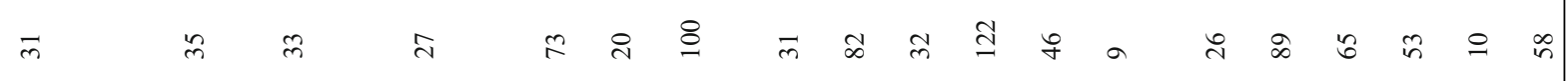

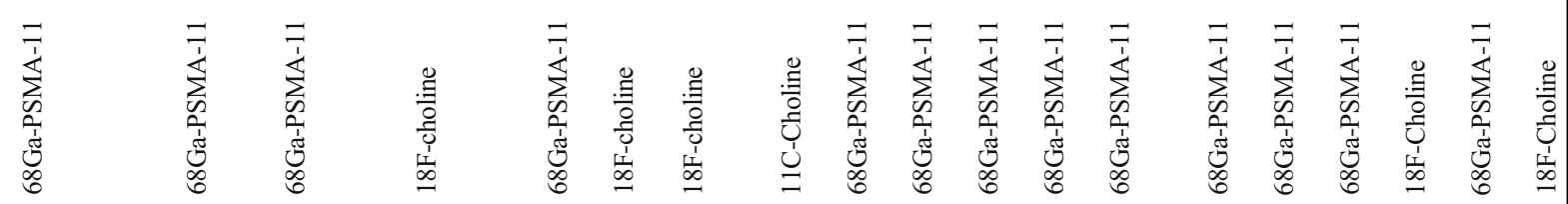

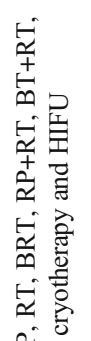

言 亮

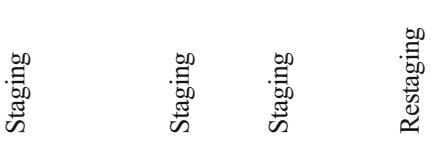

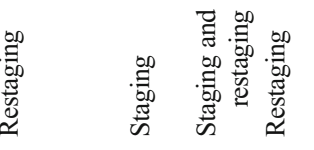

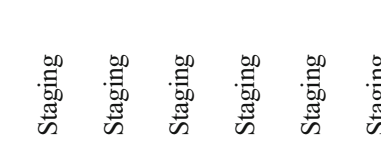

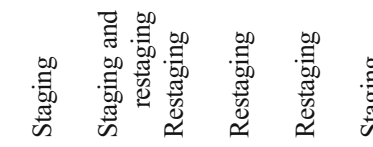

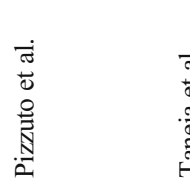

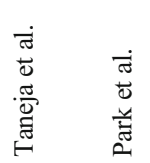

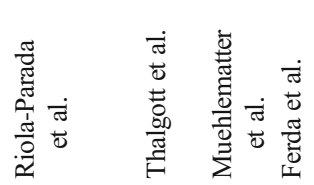

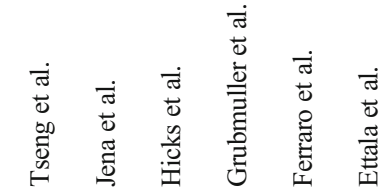

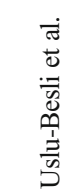

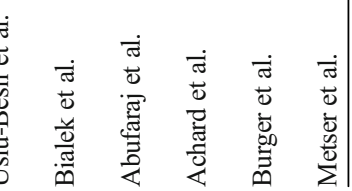


the pelvis, but distant nodes were found in the common iliac chain in 2 patients [35]. ${ }^{68} \mathrm{Ga}$-PSMA-11 PET/MRI provides valuable diagnostic information and improves patient selection for extended pelvic lymph node dissection by comparison with the currently-used clinical nomograms [38, 40, 47].

The rate of changes to patient management can express the impact of PET/MRI on the initial staging of PCa patients. Grubmuller et al. [46] reported that including PET/MRI in the initial workup of patients with PCa could alter the therapeutic strategy in at least $30 \%$ of cases.

\section{PET/MRI in cases of biochemical disease recurrence}

$\mathrm{PET} / \mathrm{MRI}$ was used to seek biochemical recurrences of $\mathrm{PCa}$ in a total of 598 patients $[8,26,32,34,39,42,51,52,56]$. Taking the studies concerned together, the recurrent disease detection rate achieved with PET/MRI ranged between 54.5 [56] and 97\% [8] (Table 2). In many cases, the authors also reported the detection rate by PSA category, which rose with antigen levels from low $(<0.2 \mathrm{ng} / \mathrm{mL})$ to high ( $>$ $10 \mathrm{ng} / \mathrm{mL}$ ). Hope et al. [26] reported a detection rate of $58-64 \%$ for PSA levels $<0.5 \mathrm{ng} / \mathrm{mL}$ using $68 \mathrm{Ga}-\mathrm{PSMA}-$ $11 \mathrm{PET} / \mathrm{MRI}$, while it was $100 \%$ for PSA $>2.0 \mathrm{ng} / \mathrm{mL}$ [26]. Grubmuller et al. [34] confirmed as much. A number of authors $[26,28,34,51]$ detected a change in patient management prompted by PET/MRI findings, in proportions of cases ranging from 53.2 to $74.6 \%$. Based on the study by Kranzbuhler et al. [56], including PET/MRI in the diagnostic workup could prompt changes to radiotherapy planning for $39.4 \%$ of patients.

\section{PET/CT vs. PET/MRI}

PET/MRI and PET/CT were compared in seven studies (Table 3; [10, 16, 20, 21, 25, 30, 59] encompassing 278 examinations, 225 of them using ${ }^{68}$ Ga-PSMA-11 (81\%) and 53 with ${ }^{11}$ C-choline (19\%).

The overall discrepancy in PET-positive findings between PET/CT and PET/MRI was very low, and agreement between the two methods was high, in the range of 71 to $95 \%$ [20, 30, $60]$; this also was applied to the semiquantitative analyses [10, 30].

Five studies demonstrated that PET/MRI was superior to $\mathrm{PET} / \mathrm{CT}$ in detecting $\mathrm{PCa}$ lesions, both in staging and restaging [16, 21, 25, 30, 59]. In particular, PET/MRI was more accurate than PET/CT in detecting local recurrences, thereby improving the detection rate for lower PSA levels. All authors [16, 21, 25, 30, 59] found the MRI component crucial in identifying local recurrences otherwise masked by the accumulation of the radiopharmaceuticals in the bladder, especially when ${ }^{68} \mathrm{Ga}$-PSMA-11 was used.

Regarding the assessment of lymph node involvement, PET/MRI achieved a slightly higher detection rate 
Risk of bias

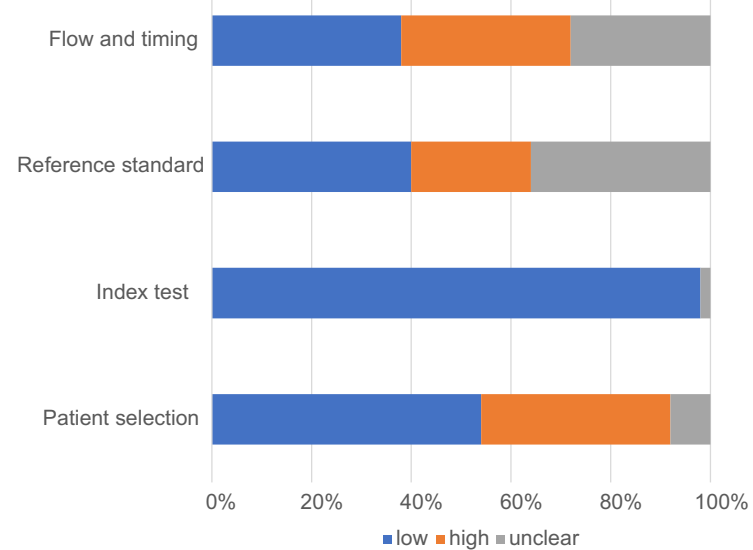

Applicability concerns

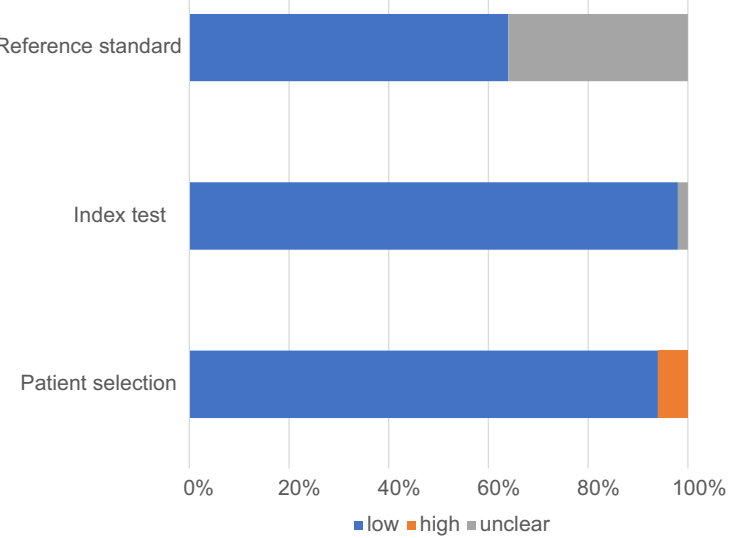

Fig. 2 QUADAS-2 findings on the qualitative assessment of the studies selected

than PET/CT, probably due to a longer tracer accumulation time, as mentioned in the studies by Freitag et al. [16] and Lutje et al. [25].

As for identifying bone metastases, Eiber et al. [21] argue that PET/CT and PET/MRI are comparable for PSA levels $<$ $2 \mathrm{ng} / \mathrm{mL}$, and that PET/CT is more efficient for levels $>2 \mathrm{ng} /$ $\mathrm{mL}$. Freitag et al. [16] and Souvatzoglou et al. [10] claim instead that using multiple MRI sequences improves the detection of bone metastases, especially in cases of early bone marrow involvement.

PET/MRI demands a $79.7 \%$ (range, 72.6-86.2\%) lower exposure to radiation than PET/CT [21, 59], but the acquisition time is much longer (60 vs. $20 \mathrm{~min}$ ) [21]. This latter aspect is relative to the inclusion of a mpMRI of the prostate/prostatic fossa that improve significantly the resolution of prostate scan.

\section{PET/MRI vs. mpMRI}

Some papers compared the PCa detection rate or diagnostic performance of PET/MRI and mpMRI in terms of sensitivity and specificity (Table 1s; [13, 14, 18, 29-33, 35, $38,45,51,52,61])$. PET/MRI achieved a higher primary tumor detection rate than mpMRI [14, 18, 45]. Judging from the data reported by de Perrot et al. [13] and Muehlematter et al. [41], PET/MRI was more sensitive than mpMRI in identifying primary tumor in the peripheral zone of prostate gland, and in revealing extracapsular extension and seminal vesicle infiltration. On the other hand, mpMRI provided more information about disease recurrence in the prostatic fossa $[30,51]$. As for the detection of lymph node and distant metastases, PET/MRI was more sensitive than mpMRI, in both staging [38] and restaging $[32,51]$.

\section{Radiolabeled PSMA vs. radiolabeled choline PET/MRI}

The most papers included radiolabeled PSMA as radiopharmaceutical agent. The majority of them were focused on 68Ga-PSMA-11 ( $n=32$ studies), while 2 were based on 18F-PSMA [31, 33]. Radiolabeled choline PET/MRI was employed in the staging for 8/16 (50\%) [11-14, 17, 29, 43, 53], while radiolabeled PSMA in 16/34 (47\%) papers [16, 18, 27, 31, 35-37, 40, 44-49, 54]. Conversely, 5/16 (31\%) [9, 21, $39,42,51]$ and $11 / 34(32 \%)$ articles $[8,23,25,26,28,30,32$, $34,52,56]$ were focused on the resting phase for radiolabeled choline and PSMA, respectively.

For the identification of primary lesion, PSMA PET/MRI enriched a specificity of $88 \%$, according to Hicks et al. [45], while choline PET/MRI registered a specificity equal to $76 \%$ [13]. Therefore, PSMA is more accurate in detecting primary $\mathrm{PCa}$ lesions, by reducing the rate of falsely positive findings. In restaging, PSMA PET/MRI showed a detection rate of $64 \%$ for PSA values $<0.5 \mathrm{ng} / \mathrm{mL}$ in 150 patients [26], therefore significantly higher than choline PET/MRI (detection rate of $12.5 \%$ in 58 patients for the same values of PSA) [51] (see Table 2).

However, no comparative data are now available about radiolabeled PSMA and choline PET/MRI in the same population, in each phase of disease (i.e., staging or restaging).

\section{Other aspects explored}

Six articles considered the image acquisition protocol $[19,23$, $24,37,48,53]$, four discussed technical aspects [15, 22, 41, 55], and eight focused on the interpretation of images obtained with PET/MRI [9, 12, 17, 27, 36, 43, 49, 50].

The best time per bed acquisition using PET/MRI for PCa is longer than $3 \mathrm{~min}[19,23]$ because this can reduce the halo 
Table 2 Detection rates of PET/MRI in restaging

\begin{tabular}{|c|c|c|c|}
\hline Authors & Ref & $N$ of pts & Detection rate \\
\hline Afshar-Oromieh et al. & [59] & 20 & $80 \%$ \\
\hline Freitag et al. & [30] & 119 & $78.2 \%$ \\
\hline Lütje et al. & {$[25]$} & 25 & $89.6 \%$ \\
\hline Hope et al. & [26] & 150 & $\begin{array}{l}82 \% \\
\text { PSA level: } \\
58 \%(<0.2 \mathrm{ng} / \mathrm{mL}) \\
64 \%(0.2-0.5 \mathrm{ng} / \mathrm{mL}) \\
64 \%(0.5-1 \mathrm{ng} / \mathrm{mL}) \\
67 \%(1-1.5 \mathrm{ng} / \mathrm{mL}) \\
100 \%(1.5-2 \mathrm{ng} / \mathrm{mL}) \\
93 \%(2-5 \mathrm{ng} / \mathrm{mL}) \\
93 \%(>5 \mathrm{ng} / \mathrm{mL}) \\
\text { PSAdt: } \\
83 \%(0-3 \text { months }) \\
90 \%(3-6 \text { months }) \\
97 \%(6-12 \text { months }) \\
88 \%(>12 \text { months })\end{array}$ \\
\hline Eiber et al. & [21] & 75 & $\begin{array}{l}84.7 \% \text { (team readers } 1) \\
85.3 \% \text { (team readers } 2)\end{array}$ \\
\hline Lake et al. & [23] & 55 & $\begin{array}{l}89.1 \% \\
\text { PSA level: } \\
75 \%(0-1 \mathrm{ng} / \mathrm{mL}) \\
80 \%(1-2 \mathrm{ng} / \mathrm{mL}) \\
94.6 \%(\geq 2 \mathrm{ng} / \mathrm{mL})\end{array}$ \\
\hline Kranzbühler et al. & {$[32]$} & 56 & $\begin{array}{l}78.6 \% \\
\text { PSA level: } \\
44.4 \%(<0.2 \mathrm{ng} / \mathrm{mL}) \\
72.7 \%(0.2<0.5 \mathrm{ng} / \mathrm{mL}) \\
80 \%(0.5-<2 \mathrm{ng} / \mathrm{mL}) \\
95.2 \%(\geq 2 \mathrm{ng} / \mathrm{mL})\end{array}$ \\
\hline Grubmüller et al.* & [34] & 117 & $\begin{array}{l}85.5 \% \\
\text { PSA level: } \\
65 \%(0.2 \text { to }<0.5 \mathrm{ng} / \mathrm{mL}) \\
85.7 \%(0.5-<1 \mathrm{ng} / \mathrm{mL}) \\
85.7 \%(1-<2 \mathrm{ng} / \mathrm{mL}) \\
100 \%(\geq 2 \mathrm{ng} / \mathrm{mL})\end{array}$ \\
\hline Riola-Parada et al. & [39] & 27 & $\begin{array}{l}55.56 \% \\
\text { PSA level: } \\
42.86 \%(<1 \mathrm{ng} / \mathrm{mL}) \\
0 \%(1-1.9 \mathrm{ng} / \mathrm{mL}) \\
75 \%(2-2.9 \mathrm{ng} / \mathrm{mL}) \\
71.43 \%(3-3.9 \mathrm{ng} / \mathrm{mL}) \\
60 \%(\geq 4 \mathrm{ng} / \mathrm{mL})\end{array}$ \\
\hline Ferda et al. & {$[42]$} & 100 & $\begin{array}{l}94 \% \\
\text { PSA level: } \\
33.3 \%(<0.2 \mathrm{ng} / \mathrm{mL}) \\
88.89 \%(0.2-2 \mathrm{ng} / \mathrm{mL}) \\
97.96 \%(2.1-5 \mathrm{ng} / \mathrm{mL}) \\
100 \%(5.1-10 \mathrm{ng} / \mathrm{mL}) \\
100 \%(\geq 10.1 \mathrm{ng} / \mathrm{mL})\end{array}$ \\
\hline Achard et al. & [51] & 58 & $\begin{array}{l}58.6 \% \\
\text { PSA level: } \\
12.5 \%(<0.5 \mathrm{ng} / \mathrm{mL}) \\
42.9 \%(0.5-1 \mathrm{ng} / \mathrm{mL}) \\
60 \%(1-2 \mathrm{ng} / \mathrm{mL}) \\
85.7 \%(\geq 2 \mathrm{ng} / \mathrm{mL})\end{array}$ \\
\hline Abufaraj et al. & [8] & 65 & $97 \%$ \\
\hline Kranzbuhler et al. & {$[56]$} & 66 & $\begin{array}{l}54.5 \% \\
\text { PSA level: } \\
38.5 \%(<0.2 \mathrm{ng} / \mathrm{mL}) \\
65 \%(0.2-0.5 \mathrm{ng} / \mathrm{mL})\end{array}$ \\
\hline
\end{tabular}

$P S A$, prostate-specific antigen; $d t$, doubling time

${ }^{*}$ Both PET/MRI and PET/CT artifact in the bladder and kidney for ${ }^{68}$ Ga-PSMA-11 [24]. According to Heußer et al. [22], the halo artifact can also be reduced by lowering the maximum scatter fraction rate.

The choice of particular MRI sequences has an important influence on the detection of local and distant metastases, as suggested by Metser et al. [53].

The correlation between the apparent diffusion coefficient (ADC) and the standardized uptake value (SUV) is controversial. Wetter et al. [9] found an inverse correlation between ADC and SUV in bone metastases. Uslu-Besli et al. [49] and Tseng et al. [43] likewise reported an inverse correlation between the maximum SUV and the metabolic tumor volume, between uptake volume product and the ADC in primary tumor, respectively. Wetter et al. [12], on the other hand, found no correlation between ADC and SUV in primary cancer.

\section{Quantitative results}

A meta-analysis was performed on 23 studies (Fig. 1), 11 concerning the staging phase $[16,18,27,35,38,40,44-47$, $52]$, and 12 the restaging phase $[8,21,23,25,26,30,32,39$, $42,51,56,59]$. Pooled sensitivities and specificities were obtained for the former (staging), and a pooled detection rate was computed for the latter (restaging).

Table 4 shows the pooled sensitivities and specificities for primary $\mathrm{PCa}$ and lymph node disease, showing a higher pooled sensitivity for primary lesions in the patient-based analysis (94.9\% [95\% CI 87.5-98.6]) than in the lesionbased analysis (61.5\% [95\% CI 40.6-79.8]). Vice versa, the pooled specificity was higher in the lesion-based analysis than in the patient-based analysis (90.9\% [95\% CI 80-97] vs. $62.5 \%$ [95\% CI 43.7-78.9], respectively). For lymph node disease, the pooled sensitivity and specificity were similar in the two types of analysis. The heterogeneity between the studies ranged between 0 and $98.3 \%$.

At restaging, the pooled detection rate was $80.9 \%$ (95\% CI 73.0-86.9\%) (Table 5). The pooled detection rate was higher for studies using PET/MRI with radiolabeled PSMA than for those with radiolabeled choline ( 81.8 vs. $77.3 \%$ ). The heterogeneity between the studies was high $(>80 \%)$. There was also evidence of publication bias, as illustrated by the funnel plot (Supplemental Figure 1).

In the studies that compared PET/CT with PET/MRI in the same population, the pooled detection rates were $95.4 \%$ (95\% CI 87.0-98.5) and 93.9\% (95\% CI 85.4-97.6), respectively; and, here again, the heterogeneity among the studies was > $80 \%$.

\section{Discussion and conclusions}

The data emerging from the available literature suggest some considerations. 
Table 3 Detection rates for radiolabeled PSMA and Choline $\mathrm{PET} / \mathrm{CT}$ vs. PET/MRI in Prostate Cancer

\begin{tabular}{|c|c|c|c|c|c|}
\hline$N$ & Authors & Ref & Type of analysis & $\begin{array}{l}\text { Detection rate PET/ } \\
\mathrm{CT}\end{array}$ & $\begin{array}{l}\text { Detection rate } \mathrm{PET} / \\
\text { MRI }\end{array}$ \\
\hline 1 & $\begin{array}{l}\text { Afshar-Oromieh } \\
\text { et al. }\end{array}$ & [59] & Lesion-based & $74 / 75(99 \%)$ & $69 / 75(92 \%)$ \\
\hline \multirow[t]{4}{*}{2} & \multirow{4}{*}{ Souvatzoglout et al. } & \multirow[t]{4}{*}[10]{} & \multirow[t]{4}{*}{ Lesion-based } & $79 / 80(99 \%)$ & $77 / 80(96 \%)$ \\
\hline & & & & LR: 19 & LR: 20 \\
\hline & & & & LN: 42 & LN: 40 \\
\hline & & & & DM: 18 & DM: 17 \\
\hline 3 & Freitag et al. & {$[16]$} & Patient-based & LR: 9/119 (8\%) & $18 / 119(16 \%)$ \\
\hline 4 & Domachevsky et al. & {$[20]$} & Lesion-based & $63 / 63(100 \%)$ & $61 / 63(97 \%)$ \\
\hline \multirow[t]{9}{*}{5} & \multirow[t]{9}{*}{ Eiber et al. } & \multirow[t]{9}{*}[21]{} & Patient-based & $58 / 75(77 \%)$ & $63 / 75(84 \%)$ \\
\hline & & & \multirow{2}{*}{$\begin{array}{l}\text { Lesion-based } \\
\quad(\mathrm{R}-1)\end{array}$} & $155 / 188(82 \%)$ & $148 / 188(79 \%)$ \\
\hline & & & & LR: 24 & LR: 36 \\
\hline & & & \multirow{6}{*}{$\begin{array}{l}\text { Lesion-based } \\
\quad(\mathrm{R}-2)\end{array}$} & LN: 74 & LN: 60 \\
\hline & & & & DM: 57 & DM: 52 \\
\hline & & & & $160 / 188(85 \%)$ & $143 / 188(76 \%)$ \\
\hline & & & & LR: 36 & LR: 32 \\
\hline & & & & LN: 72 & LN: 60 \\
\hline & & & & DM: 62 & DM: 51 \\
\hline \multirow[t]{4}{*}{6} & \multirow[t]{4}{*}{ Lutje et al. } & \multirow[t]{4}{*}[25]{} & \multirow[t]{4}{*}{ Lesion-based } & $36 / 46(78 \%)$ & $43 / 46(93 \%)$ \\
\hline & & & & LR: 9 & LR: 14 \\
\hline & & & & LN: 20 & LN: 23 \\
\hline & & & & DM: 7 & DM: 6 \\
\hline 7 & Freitag et al. & {$[30]$} & Lesion-based & $89 / 90(99 \%)$ & $90 / 90(100 \%)$ \\
\hline
\end{tabular}

$L R$ local recurrence, $L N$ lymph node, $D M$ distant metastasis; $R$ reader
1). The ability of PET/MRI with radiolabeled PSMA to detect dominant lesions (pooled sensitivity for sextantbased analysis, $80 \%$ ) may suggest a further search on prostate fusion biopsy of the suspected area. A recent paper by Westphalen et al. [62] reported a low positive predictive value (PPV) of PI-RADS for identifying primary PCa. After reviewing mpMRI images from 3449 patients for a total of 5082 lesions, the authors found a PPV of 5\% for PI-RADS 2, 15\% for PI-RADS 3, 39\% for PI-RADS 4, and $72 \%$ for PI-RADS 5. Park et al. [38] found that PET/MRI with 68Ga-PSMA-11 had a higher PPV than mpMRI for bilateral tumors ( 70 vs. $18 \%$, respectively). Two articles discussed about the role of PET/ MRI for the diagnosis of PCa. Taneja et al. [37] and Jena et al. [44] showed that dual-phase simultaneous 68GaPSMA-11 PET/MRI is able to characterize prostate lesions, in 117 patients. In particular, Taneja et al. reported that malignant lesions have higher PSMA uptake than the benign ones, mainly in the delayed images (acquired after about $50 \mathrm{~min}$ form tracer injection) due to a possible

Table 4 Pooled sensitivity and specificity for staging

\begin{tabular}{|c|c|c|c|c|c|c|}
\hline $\begin{array}{l}\text { Site of disease (type of } \\
\text { analysis) }\end{array}$ & $\begin{array}{l}\text { Pooled sensitivity } \\
(95 \% \mathrm{CI})\end{array}$ & $\begin{array}{l}\text { Heterogeneity }(P \\
\text { value) }\end{array}$ & $\begin{array}{l}I \text {-square } \\
(\%)\end{array}$ & $\begin{array}{l}\text { Pooled specificity } \\
(95 \% \mathrm{CI})\end{array}$ & $\begin{array}{l}\text { Heterogeneity ( } P \\
\text { value) }\end{array}$ & $\begin{array}{l}I \text {-square } \\
(\%)\end{array}$ \\
\hline Primary tumor (per-lesion) & $61.5 \%(40.6-79.8)$ & $0.39(0.531)$ & 0 & $90.9 \%(80-97)$ & $8.05(0.005)$ & 87.6 \\
\hline Primary tumor (per-patient) & $94.9 \%(87.5-98.6)$ & $3.14(0.076)$ & 68.2 & $62.5 \%(43.7-78.9)$ & $0.32(0.571)$ & 0 \\
\hline Primary tumor (sextant-based) & $79.3 \%(76-82.3)$ & $68.28(<0.005)$ & 98.3 & $83.4 \%(80.2-86.3)$ & $27.16(<0.005)$ & 96.3 \\
\hline $\begin{array}{l}\text { Lymph node metastases } \\
\text { (per-lesion) }\end{array}$ & $64.3 \%(44.1-81.4)$ & $2.85(0.091)$ & 64.9 & $97.4 \%(91-99.7)$ & $3.91(0.048)$ & 74.4 \\
\hline $\begin{array}{l}\text { Lymph node metastases } \\
\text { (per-patient) }\end{array}$ & $66.7 \%(49.8-80.9)$ & $0.58(0.748)$ & 0 & $93.4 \%(87.5-97.1)$ & $37.12(<0.005)$ & 94.6 \\
\hline
\end{tabular}

$C I$ confidence interval 
Table 5 Pooled detection rate in restaging

\begin{tabular}{llll}
\hline & Pooled detection rate $(95 \% \mathrm{CI})$ & Heterogeneity $(P$ value $)$ & $I$-square \\
\hline All reports & $80.9 \%(73.0-86.9)$ & $59.531(<0.005)$ & 81.522 \\
PSMA PET/MRI & $81.8 \%(72.4-88.4)$ & $35.014(<0.005)$ & 80.008 \\
Choline PET/MRI & $77.3 \%(53.7-90.9)$ & $24.508(<0.005)$ & 87.759 \\
PET/CT vs. PET/MRI & $95.4 \%(87.0-98.5)$ & $28.222(<0.005)$ & 82.283 \\
& $93.9 \%(85.4-97.6)$ & $28.812(<0.005)$ & 82.646 \\
\hline
\end{tabular}

CI confidence interval role of receptor density and longer retention of PSMA in PCa over time. Moreover, Jena et al. [44] concluded that combining PET data, MRI data, PSA levels, and digital rectal examination resulted in a better characterization of prostatic lesions, with an AUC of $0.94 \pm 0.29$. However, in the setting of primary PCa, MRI-TRUS fusion biopsy using mpMRI will remain the standard for prostate cancer probably for longer time due to a very high-quality study [63]. Similar studies for PSMA PET/MRI-guided biopsy are needed to compete with mpMRI in order to elucidate the advantages in terms of diagnostic efficiency and costs.

Although the detection of more lesions by use of PET/ MRI in primary setting may not necessarily lead to better outcome in general, the identification of oligometastasic disease would be useful for guiding to an appropriate treatment management (extension of the radiation field, extension of lymph node adenectomy, etc.) therefore allowing a long-term prognosis of the patients.

2). Targeted therapies could be directed by PET/MRI with radiolabeled PSMA because of its ability both to detect the most aggressive lesion and to assess the extracapsular extension of disease. This latter information would be useful not only to guide to more precise surgical approach, but it can be useful for focal or less-invasive treatments.

3). PET/MRI with radiolabeled PSMA could be used for early disease recurrences (PSA levels $<0.5 \mathrm{ng} / \mathrm{mL}$ ) because it can raise the detection rate to $65 \%$ and could also be helpful in guiding MDT. It seems that mpMRI can suffice for identifying PCa recurrences in the prostatic fossa. However, the added value of PET/MRI is its ability to detect also the lymph node involvement thus guiding to a specific salvage therapy, especially in case of radiotherapy. Furthermore, in case of a positivity only in the lymph node, a salvage lymph node dissection can be planned, by evaluating also the possible nerve or other neighboring structure involvement.

4). PSMA PET/MRI is more detectable than choline PET/ MRI in staging and in restaging, although head to head comparative data are missing.

5). PSMA PET/MRI can prompt changes to the management of PCa patients in up to $75 \%$ of cases at restaging.
It means that in population of 100 patients with a $\mathrm{PCa}$, the inclusion of PET/MRI in the diagnostic algorithm has a deep effect on the management and therefore on the short- and long-term prognosis. However, more data are necessary for this latter indication, being the literature scarce.

This hybrid imaging modality has some limitations, however, such as the need for scatter correction and long acquisition times. The accurate description and interpretation of the results are also key challenges for radiologists/specialists in nuclear medicine and urologists alike.

In short, PET/MRI seems to have potential applications in the following: (1) the diagnosis of primary tumor; (2) facilitating biopsy targeting; (3) predicting or monitoring tumor aggressiveness (especially during active surveillance); (4) the early detection of recurrent $\mathrm{PCa}$; and (5) guiding targeted therapies.

Acknowledgments The authors are thankful to Prof. Kilian Schiller (Technical University of Munich, Munich, Germany) for his help in the recovery of some useful data.

Funding Open access funding provided by Università degli Studi di Padova within the CRUI-CARE Agreement.

\section{Compliance with ethical standards}

Conflict of interest The authors declare that they have no conflict of interest.

Human and animal rights This article does not contain any studies with human participants or animals performed by any of the authors.

Informed consent For this type of study, informed consent is not required.

Open Access This article is licensed under a Creative Commons Attribution 4.0 International License, which permits use, sharing, adaptation, distribution and reproduction in any medium or format, as long as you give appropriate credit to the original author(s) and the source, provide a link to the Creative Commons licence, and indicate if changes were made. The images or other third party material in this article are included in the article's Creative Commons licence, unless indicated otherwise in a credit line to the material. If material is not included in the article's Creative Commons licence and your intended use is not permitted by statutory regulation or exceeds the permitted use, you will 
need to obtain permission directly from the copyright holder. To view a copy of this licence, visit http://creativecommons.org/licenses/by/4.0/.

\section{References}

1. Lecouvet FE, Oprea-Lager DE, Liu Y, Ost P, Bidaut L, Collette L, et al. Use of modern imaging methods to facilitate trials of metastasis-directed therapy for oligometastatic disease in prostate cancer: a consensus recommendation from the EORTC Imaging Group. Lancet Oncol. 2018;19:e534-e45.

2. Vogel MME, Kroeze SGC, Henkenberens C, Schmidt-Hegemann NS, Kirste S, Becker J, et al. Prognostic risk classification for biochemical relapse-free survival in patients with oligorecurrent prostate cancer after $\left[{ }^{68} \mathrm{Ga}\right]$ PSMA-PET-guided metastasis-directed therapy. Eur J Nucl Med Mol Imaging. 2020;47:2328-38. https://doi. org/10.1007/s00259-020-04760-8.

3. Cimitan M, Evangelista L, Hodolic M, Mariani G, Baseric T, Bodanza $\mathrm{V}$, et al. Gleason score at diagnosis predicts the rate of detection of $18 \mathrm{~F}$-choline PET/CT performed when biochemical evidence indicates recurrence of prostate cancer: experience with 1,000 patients. J Nucl Med. 2015;56:209-15.

4. Graziani T, Ceci F, Castellucci P, Polverari G, Lima GM, Lodi F, et al. (11)C-choline PET/CT for restaging prostate cancer. Results from 4,426 scans in a single-centre patient series. Eur J Nucl Med Mol Imaging. 2016;43:1971-9.

5. Fendler WP, Calais J, Eiber M, Flavell RR, Mishoe A, Feng FY, et al. Assessment of 68Ga-PSMA-11 PET accuracy in localizing recurrent prostate cancer: a prospective single-arm clinical trial. JAMA Oncol. 2019;5:856-63.

6. Whiting PF, Rutjes AW, Westwood ME, Mallett S, Deeks JJ, Reitsma JB, et al. QUADAS-2: a revised tool for the quality assessment of diagnostic accuracy studies. Ann Intern Med. 2011;155: 529-36.

7. Higgins JP, Thompson SG, Deeks JJ, Altman DG. Measuring inconsistency in meta-analyses. BMJ. 2003;327:557-60.

8. Abufaraj M, Grubmuller B, Zeitlinger M, Kramer G, Seitz C, Haitel A, et al. Prospective evaluation of the performance of $[(68) \mathrm{Ga}] \mathrm{Ga}-$ PSMA-11 PET/CT(MRI) for lymph node staging in patients undergoing superextended salvage lymph node dissection after radical prostatectomy. Eur J Nucl Med Mol Imaging. 2019;46:2169-77.

9. Wetter A, Lipponer C, Nensa F, Heusch P, Rubben H, Schlosser $\mathrm{TW}$, et al. Quantitative evaluation of bone metastases from prostate cancer with simultaneous [18F] choline PET/MRI: combined SUV and ADC analysis. Ann Nucl Med. 2014;28:405-10.

10. Souvatzoglou M, Eiber M, Takei T, Furst S, Maurer T, Gaertner F, et al. Comparison of integrated whole-body [11C]choline PET/MR with PET/CT in patients with prostate cancer. Eur J Nucl Med Mol Imaging. 2013;40:1486-99.

11. Wetter A, Lipponer C, Nensa F, Heusch P, Rubben H, Altenbernd $\mathrm{JC}$, et al. Evaluation of the PET component of simultaneous $[(18) \mathrm{F}]$ choline PET/MRI in prostate cancer: comparison with [(18)F]choline PET/CT. Eur J Nucl Med Mol Imaging. 2014;41: 79-88.

12. Wetter A, Nensa F, Schenck M, Heusch P, Poppel T, Bockisch A, et al. Combined PET imaging and diffusion-weighted imaging of intermediate and high-risk primary prostate carcinomas with simultaneous [18F] choline PET/MRI. PLoS One. 2014;9:e101571.

13. de Perrot T, Rager O, Scheffler M, Lord M, Pusztaszeri M, Iselin C, et al. Potential of hybrid (1)(8)F-fluorocholine PET/MRI for prostate cancer imaging. Eur J Nucl Med Mol Imaging. 2014;41:1744-55.

14. Kim YI, Cheon GJ, Paeng JC, Cho JY, Kwak C, Kang KW, et al. Usefulness of MRI-assisted metabolic volumetric parameters provided by simultaneous (18)F-fluorocholine PET/MRI for primary prostate cancer characterization. Eur J Nucl Med Mol Imaging. 2015;42:1247-56.

15. Gatidis S, Scharpf M, Martirosian P, Bezrukov I, Kustner T, Hennenlotter J, et al. Combined unsupervised-supervised classification of multiparametric PET/MRI data: application to prostate cancer. NMR Biomed. 2015;28:914-22.

16. Freitag MT, Radtke JP, Hadaschik BA, Kopp-Schneider A, Eder M, Kopka K, et al. Comparison of hybrid (68)Ga-PSMA PET/MRI and (68)Ga-PSMA PET/CT in the evaluation of lymph node and bone metastases of prostate cancer. Eur J Nucl Med Mol Imaging. 2016;43:70-83.

17. Wetter A, Gruneisen J, Fliessbach K, Lutje S, Schaarschmidt B, Umutlu L. Choline-based imaging of prostate cancer with combined [(18)F] fluorocholine PET and (1)H MR spectroscopy by means of integrated PET/MRI. Clin Imaging. 2017;42:198-202.

18. Eiber M, Weirich G, Holzapfel K, Souvatzoglou M, Haller B, Rauscher I, et al. Simultaneous (68)Ga-PSMA HBED-CC PET/ MRI improves the localization of primary prostate cancer. Eur Urol. 2016;70:829-36.

19. Lutje S, Blex S, Gomez B, Schaarschmidt BM, Umutlu L, Forsting $\mathrm{M}$, et al. Optimization of acquisition time of 68Ga-PSMA-ligand PET/MRI in patients with local and metastatic prostate cancer. PLoS One. 2016;11:e0164392.

20. Domachevsky L, Bernstine H, Goldberg N, Nidam M, Stern D, Sosna J, et al. Early (68)GA-PSMA PET/MRI acquisition: assessment of lesion detectability and PET metrics in patients with prostate cancer undergoing same-day late PET/CT. Clin Radiol. 2017;72:944-50.

21. Eiber M, Rauscher I, Souvatzoglou M, Maurer T, Schwaiger M, Holzapfel K, et al. Prospective head-to-head comparison of (11)Ccholine-PET/MR and (11)C-choline-PET/CT for restaging of biochemical recurrent prostate cancer. Eur J Nucl Med Mol Imaging. 2017;44:2179-88.

22. Heusser T, Mann P, Rank CM, Schafer M, DimitrakopoulouStrauss A, Schlemmer HP, et al. Investigation of the halo-artifact in 68Ga-PSMA-11-PET/MRI. PLoS One. 2017;12:e0183329.

23. Lake ST, Greene KL, Westphalen AC, Behr SC, Zagoria R, Small EJ, et al. Optimal MRI sequences for (68)Ga-PSMA-11 PET/MRI in evaluation of biochemically recurrent prostate cancer. EJNMMI Res. 2017;7:77.

24. Noto B, Buther F, Auf der Springe K, Avramovic N, Heindel W, Schafers $\mathrm{M}$, et al. Impact of PET acquisition durations on image quality and lesion detectability in whole-body (68)Ga-PSMA PETMRI. EJNMMI Res. 2017;7:12.

25. Lutje S, Cohnen J, Gomez B, Gruneisen J, Sawicki L, Rubben H, et al. Integrated (68)Ga-HBED-CC-PSMA-PET/MRI in patients with suspected recurrent prostate cancer. Nuklearmedizin. 2017;56:73-81.

26. Hope TA, Aggarwal R, Chee B, Tao D, Greene KL, Cooperberg $\mathrm{MR}$, et al. Impact of (68)Ga-PSMA-11 PET on management in patients with biochemically recurrent prostate cancer. J Nucl Med. 2017;58:1956-61.

27. Bates A, Miles K. Prostate-specific membrane antigen PET/MRI validation of MR textural analysis for detection of transition zone prostate cancer. Eur Radiol. 2017;27:5290-8.

28. Schiller K, Sauter K, Dewes S, Eiber M, Maurer T, Gschwend J, et al. Patterns of failure after radical prostatectomy in prostate cancer - implications for radiation therapy planning after (68)GaPSMA-PET imaging. Eur J Nucl Med Mol Imaging. 2017;44: 1656-62.

29. Lee MS, Cho JY, Kim SY, Cheon GJ, Moon MH, Oh S, et al. Diagnostic value of integrated PET/MRI for detection and localization of prostate cancer: comparative study of multiparametric MRI and PET/CT. J Magn Reson Imaging. 2017;45:597-609. 
30. Freitag MT, Radtke JP, Afshar-Oromieh A, Roethke MC, Hadaschik BA, Gleave M, et al. Local recurrence of prostate cancer after radical prostatectomy is at risk to be missed in (68)Ga-PSMA11-PET of PET/CT and PET/MRI: comparison with mpMRI integrated in simultaneous PET/MRI. Eur J Nucl Med Mol Imaging. 2017;44:776-87.

31. Bauman G, Martin P, Thiessen JD, Taylor R, Moussa M, Gaed M, et al. [(18)F]-DCFPyL positron emission tomography/magnetic resonance imaging for localization of dominant intraprostatic foci: first experience. Eur Urol Focus. 2018;4:702-6.

32. Kranzbuhler B, Nagel H, Becker AS, Muller J, Huellner M, Stolzmann P, et al. Clinical performance of (68)Ga-PSMA-11 PET/MRI for the detection of recurrent prostate cancer following radical prostatectomy. Eur J Nucl Med Mol Imaging. 2018;45:2030 .

33. Freitag MT, Kesch C, Cardinale J, Flechsig P, Floca R, Eiber M, et al. Simultaneous whole-body (18)F-PSMA-1007-PET/MRI with integrated high-resolution multiparametric imaging of the prostatic fossa for comprehensive oncological staging of patients with prostate cancer: a pilot study. Eur J Nucl Med Mol Imaging. 2018;45: $340-7$.

34. Grubmuller B, Baltzer P, D'Andrea D, Korn S, Haug AR, Hacker $\mathrm{M}$, et al. (68)Ga-PSMA 11 ligand PET imaging in patients with biochemical recurrence after radical prostatectomy - diagnostic performance and impact on therapeutic decision-making. Eur J Nucl Med Mol Imaging. 2018;45:235-42.

35. Al-Bayati M, Grueneisen J, Lutje S, Sawicki LM, Suntharalingam $\mathrm{S}$, Tschirdewahn S, et al. Integrated 68gallium labelled prostatespecific membrane antigen-11 positron emission tomography/ magnetic resonance imaging enhances discriminatory power of multi-parametric prostate magnetic resonance imaging. Urol Int. 2018;100:164-71.

36. Pizzuto DA, Muller J, Muhlematter U, Rupp NJ, Topfer A, Mortezavi A, et al. The central zone has increased (68)GaPSMA-11 uptake: "Mickey Mouse ears" can be hot on (68)GaPSMA-11 PET. Eur J Nucl Med Mol Imaging. 2018;45:1335-43.

37. Taneja S, Jena A, Taneja R, Singh A, Ahuja A. Effect of combined (68)Ga-PSMAHBED-CC uptake pattern and multiparametric MRI derived with simultaneous PET/MRI in the diagnosis of primary prostate cancer: initial experience. AJR Am J Roentgenol. 2018;210:1338-45.

38. Park SY, Zacharias C, Harrison C, Fan RE, Kunder C, Hatami N, et al. Gallium 68 PSMA-11 PET/MR imaging in patients with intermediate- or high-risk prostate cancer. Radiology. 2018;288: 495-505.

39. Riola-Parada C, Carreras-Delgado JL, Perez-Duenas V, GarcerantTafur M, Garcia-Canamaque L. (18)F-choline PET/MRI in suspected recurrence of prostate carcinoma. Rev Esp Med Nucl Imagen Mol. 2018;37:296-301.

40. Thalgott M, Duwel C, Rauscher I, Heck MM, Haller B, Gafita A, et al. One-stop-shop whole-body (68)Ga-PSMA-11 PET/MRI compared with clinical nomograms for preoperative $\mathrm{T}$ and $\mathrm{N}$ staging of high-risk prostate cancer. J Nucl Med. 2018;59:1850-6.

41. Muehlematter UJ, Nagel HW, Becker A, Mueller J, Vokinger KN, de Galiza Barbosa F, et al. Impact of time-of-flight PET on quantification accuracy and lesion detection in simultaneous (18)F-choline PET/MRI for prostate cancer. EJNMMI Res. 2018;8:41.

42. Ferda J, Ferdova E, Baxa J, Finek J, Topolcan O. (18)FFluorocholine PET/MRI in restaging of prostatic carcinoma in relation to PSA level and detection of active disease. Anticancer Res. 2018;38:4139-43.
43. Tseng JR, Yang LY, Lin YC, Liu CY, Pang ST, Hong JH, et al. Metabolic volumetric parameters in (11)C-choline PET/MR are superior PET imaging biomarkers for primary high-risk prostate cancer. Contrast Media Mol Imaging. 2018;2018:8945130.

44. Jena A, Taneja R, Taneja S, Singh A, Kumar V, Agarwal A, et al. Improving diagnosis of primary prostate cancer with combined (68)Ga-prostate-specific membrane antigen-HBED-CC simultaneous PET and multiparametric MRI and clinical parameters. AJR Am J Roentgenol. 2018;211:1246-53.

45. Hicks RM, Simko JP, Westphalen AC, Nguyen HG, Greene KL, Zhang L, et al. Diagnostic accuracy of (68)Ga-PSMA-11 PET/MRI compared with multiparametric MRI in the detection of prostate cancer. Radiology. 2018;289:730-7.

46. Grubmuller B, Baltzer P, Hartenbach S, D'Andrea D, Helbich TH, Haug AR, et al. PSMA ligand PET/MRI for primary prostate cancer: staging performance and clinical impact. Clin Cancer Res. 2018;24:6300-7.

47. Ferraro DA, Muehlematter UJ, Garcia Schuler HI, Rupp NJ, Huellner M, Messerli M, et al. (68)Ga-PSMA-11 PET has the potential to improve patient selection for extended pelvic lymph node dissection in intermediate to high-risk prostate cancer. Eur J Nucl Med Mol Imaging. 2020;47:147-59.

48. Ettala O, Malaspina S, Tuokkola T, Luoto P, Loyttyniemi E, Bostrom PJ, et al. Prospective study on the effect of short-term androgen deprivation therapy on PSMA uptake evaluated with (68)Ga-PSMA-11 PET/MRI in men with treatment-naive prostate cancer. Eur J Nucl Med Mol Imaging. 2020;47:665-73.

49. Uslu-Besli L, Bakir B, Asa S, Guner E, Demirdag C, Sahin OE, et al. Correlation of SUVmax and apparent diffusion coefficient values detected by Ga-68 PSMA PET/MRI in primary prostate lesions and their significance in lymph node metastasis: preliminary results of an on-going study. Mol Imaging Radionucl Ther. 2019;28:104-11.

50. Bialek EJ, Malkowski B. Are superior cervical sympathetic ganglia avid on whole body 68Ga-PSMA-11 PET/magnetic resonance?: a comprehensive morphologic and molecular assessment in patients with prostate cancer. Nucl Med Commun. 2019;40:1105-11.

51. Achard V, Lamanna G, Denis A, De Perrot T, Mainta IC, Ratib O, et al. Recurrent prostate cancer after radical prostatectomy: restaging performance of $18 \mathrm{~F}$-choline hybrid PET/MRI. Med Oncol. 2019;36:67.

52. Burger IA, Muller J, Donati OF, Ferraro DA, Messerli M, Kranzbuhler B, et al. (68)Ga-PSMA-11 PET/MR detects local recurrence occult on mpMRI in prostate cancer patients after HIFU. J Nucl Med. 2019;60:1118-23.

53. Metser U, Chan R, Veit-Haibach P, Ghai S, Tau N. Comparison of MRI sequences in whole-body PET/MRI for staging of patients with high-risk prostate cancer. AJR Am J Roentgenol. 2019;212: 377-81.

54. Muehlematter UJ, Burger IA, Becker AS, Schawkat K, Hotker AM, Reiner CS, et al. Diagnostic accuracy of multiparametric MRI versus (68)Ga-PSMA-11 PET/MRI for extracapsular extension and seminal vesicle invasion in patients with prostate cancer. Radiology. 2019;293:350-8.

55. Domachevsky L, Goldberg N, Gorenberg M, Bernstine H, Groshar D, Catalano OA. Prostate cancer evaluation using PET quantification in (68)Ga-PSMA-11 PET/MR with attenuation correction of bones as a fifth compartment. Quant Imaging Med Surg. 2020;10: $40-7$.

56. Kranzbuhler B, Muller J, Becker AS, Garcia Schuler HI, Muehlematter U, Fankhauser CD, et al. Detection rate and 
localization of prostate cancer recurrence using (68)Ga-PSMA-11 PET/MRI in patients with low PSA values $</=0.5 \mathrm{ng} / \mathrm{mL}$. J Nucl Med. 2020;61:194-201.

57. Nagao T, Makino Y, Yamamoto K, Urabe I, Okada H. Stabilityincreasing mutants of glucose dehydrogenase. FEBS Lett. 1989;253:113-6.

58. Ball MM, Gomez W, Magallanes X, Rosales R, Melfo A, Yarzabal LA. Bacteria recovered from a high-altitude, tropical glacier in Venezuelan Andes. World J Microbiol Biotechnol. 2014;30:931-41.

59. Afshar-Oromieh A, Haberkorn U, Schlemmer HP, Fenchel M, Eder $\mathrm{M}$, Eisenhut M, et al. Comparison of PET/CT and PET/MRI hybrid systems using a 68Ga-labelled PSMA ligand for the diagnosis of recurrent prostate cancer: initial experience. Eur J Nucl Med Mol Imaging. 2014;41:887-97.

60. Lamanna G, Tabouret-Viaud C, Rager O, Jorcano S, Vees HJ, Seimbille Y, et al. Long-term results of a comparative PET/CT and PET/MRI study of $11 \mathrm{C}$-acetate and 18F-fluorocholine for restaging of early recurrent prostate cancer. Clin Nucl Med. 2017;42:e242-e6.

61. Sarkanen T, Alakuijala A, Julkunen I, Partinen M. Narcolepsy associated with Pandemrix vaccine. Curr Neurol Neurosci Rep. 2018;18:43.

62. Westphalen AC, McCulloch CE, Anaokar JM, Arora S, Barashi NS, Barentsz JO, et al. Variability of the positive predictive value of PI-RADS for prostate MRI across 26 centers: experience of the society of abdominal radiology prostate cancer disease-focused panel. Radiology. 2020;296:76-84. https://doi.org/10.1148/radiol. 2020190646.

63. Kasivisvanathan V, Rannikko AS, Borghi M, et al. MRI-targeted or standard biopsy for prostate-Cancer diagnosis. N Engl J Med. 2018;378:1767-77.

Publisher's note Springer Nature remains neutral with regard to jurisdictional claims in published maps and institutional affiliations. 